Journal of Social Sciences 6 (3): 393-398, 2010

ISSN 1549-3652

(C) 2010 Science Publications

\title{
A Study of the Relationship Between Schooling and Enterprises' Demands for Talents
}

\author{
Chien-Hua Wang \\ Department of Business Administration, Hsing Wu College, No. 101, Sec. 1, \\ Fenliao Rd., LinKou Township, Taipei County 244, Taiwan, ROC
}

\begin{abstract}
Problem statement: In this study, job vacancies in accountancy were used as examples to explore the relationship between schooling and enterprises' demands for talents. Data of job vacancies and demands in accountancy from 2005-2009 were obtained from the well-known 1111 Job Bank. Approach: The grey prediction of the grey theory was applied to predict possible number of job vacancies in accountancy and trend in 2010 and 2011. Results: According to the test results and predictions, the number of job vacancies in accountancy will increase stably in the coming two years. Conclusion: The advantage of this study provided a practical framework, the sources of accountants in enterprises are mainly students graduated from vocational schools and senior high schools. Usually, having studied in accounting related departments is not a requirement for the jobs.
\end{abstract}

Key words: Grey theory, grey prediction, accountancy, small and medium enterprises, talent

\section{INTRODUCTION}

In the early days, under the clear guidance of the government, industries in Taiwan had been developed aggressively. Lots of technical talents of all levels had been developed and become the foundation of today's Taiwan, the center of processing industries in the world with strong competitiveness. Back then, the government had encouraged establishment of private technical schools, vocational schools and institutes of technology. Therefore, there had been lots of talents the society and enterprises need in Taiwan. After 50 years of hard work, some of the technicians in those days are now business owners who not only possess unique techniques in processing, but also have established small and medium enterprises noted by the world. This was called the "economic miracle" of the world.

With the richness of the nation and the continuous development of the society, the service trade in Taiwan has risen with the economic output value exceeding two times that in the industry. At the same time, departments of schools of all levels and job vacancies from enterprises in Taiwan have drawn part of students to the field of service trade. Gradually, there are fewer and fewer students in departments related to industry or commerce. Currently, some vocational schools are having problems enrolling new students for commercerelated departments, resulting in departments transforming into service-trade-related departments. In the recent years, the hottest departments are "department of catering", "department of tourism" and "department of leisure management". According to the statistics from the Ministry of Education, in 2009, there were 78,423 students studying in departments related to catering and tourism, while there were only 25,119 students in departments related to accounting, which was only $1 / 3$ of the number of students in departments related to catering and tourism. All major enterprises are in need of professional talents. Some of them have already started to hire professionals from other countries.

If, nowadays, the center of national policies is not development of education and market mechanism is not regulated, schools would have to establish popular departments for their survival, eventually resulting in chaos in the job market. Enterprises wouldn't be able to find talents they need. There wouldn't be many job opportunities in the service trade. However, there would be a lot of university students. This vicious circle may lead to the waste of educational resources without improvements of international competitiveness of enterprises in Taiwan. Finally, the national and its people would become poor. People in Taiwan would have to go abroad to pursue better job opportunities. Because of this, in this study, job vacancies in accountancy were used as examples to explore the relationship between schooling and enterprises' demands for talents.

Analysis of enterprises' demands for talents in accounting profession: The job content of an accountant is to systematically and clearly record 
(journal entries and posting), summarize (trial balance), organize (adjustment, balancing the books and creating tables), analyze and use enterprises' financial event data, which is technical. The purposes of developing accounting is to provide tax bureaus bases of "taxation", to provide enterprise managements references for their "management decisions" and to provide shareholders, creditors and other related people "credit references".

According to the job categories defined by the directorate-general of budget, accounting and statistics, accountants are listed under professional personnel, technicians and professional assistants and administrative personnel. The accounting related jobs can approximately be categorized into CPA firms, accounting firms, CPB firms, enterprise accounting, accountants and external audit organizations for CPA firms and accounting firms. The customers they serve are of different levels. Barrar et al. (2002) said that the job content of enterprise accounting is internal audit including affairs of financial accounting, cost accounting and managerial accounting. Accountant is an independent professional job to provide services of creating financial reports, tax attestation and planning and design of accounting systems to enterprises. As for accounting personnel in accounting firms and CPB firms, the job content includes account handling, tax declaration and planning, business registration, tax consulting, personal financial management and declaration of and suggestions on inheritance tax and gift tax. Usually, accountants and their assistants shall not only possess professional accounting abilities, but also know how to operate audit software (such as tax accounting software) and access database. The importance of language abilities (English and third language) increases with the level of job position. Familiarity with Commercial Law and other tax laws is necessary to find out the optimal solution under the complex and intricate laws and regulations.

In the aspect of educational background, $55 \%$ of the enterprises wanted to hire (vocational) senior high school graduates, $9.6 \%$ of them wanted to hire vocational school graduates and $35.3 \%$ of them wanted to hire university or higher school graduates. Nowadays, enterprises' development is very fast. Therefore, many enterprises prefer not to use people without job experiences, in order to reduce the cost of investment in employees and the loss due to fast turnover. The data from Directorate-General of Budget, Accounting and Statistics, Executive Yuan supported this fact. $56 \%$ of the enterprises wished to hire accounting personnel with $1 \sim 3$ years of experiences, $6.7 \%$ of them wished to hire accounting personnel with
$3 \sim 5$ years of experiences, $12.5 \%$ of them wished to hire accounting personnel with over 5 years of experiences and $24.9 \%$ of them didn't have any limitations in seniority. Furthermore, according to the statistics in August, 2009, the number of job vacancies in the fields of accounting, bookkeeping and financial/security assistants was 403. $29.3 \%$ of them must be (vocational) senior high school graduates, $28.8 \%$ vocational school graduates, $40.0 \%$ university graduates and $1 \%$ without limitation in educational background. Because assistants are administrative personnel, enterprises' standards for their job experiences were rather low. $12.9 \%$ of the enterprises wished to hire accounting personnel with 1 3 years of experiences, $4.5 \%$ of them wished to hire accounting personnel with $3 \sim 5$ years of experiences, none of them wished to hire accounting personnel with over 5 years of experiences and up to $82.6 \%$ of them didn't have any limitations in seniority.

According to the survey in August, 2009 by Directorate-General of Budget, Accounting and Statistics, Executive Yuan, the reasons of manpower shortage in the fields of accounting, statistics, math and related assistants include: increasing volume of business, seasons, organization change, disqualified skills of current employees, turnover, dirty and dangerous working environment, laws and regulations and other factors. $64 \%$ of the enterprises encountered manpower shortage due to increasing volume of business, only $4.5 \%$ due to organization change, $32.7 \%$ due to turnover and only $0.3 \%$ due to laws and regulations. Judging from the analysis result, increasing volume of business might have been a consequence of cutting down employees during the financial crisis (Yuehua and Wie, 2008). As for the fields of accounting, bookkeeping and financial/security assistants, $25.8 \%$ of the enterprises encountered manpower shortage due to increasing volume of business and up to $74.2 \%$ due to turnover. Since assistants are administrative personnel, they weren't paid well. Therefore, turnover was high. New employees usually left their jobs right after getting some experiences. The causes might have been heavy workload and their preference of getting other jobs in companies with better conditions after having some experiences.

Analysis of job vacancies and job hunting in accountancy: According to the job-hunting data from the well-known 1111 Job Bank in Taiwan, there had been 4,920,000 resumes uploaded and 172,000 companies recruiting by the end of January, 2010. It is found from the data that the number of vacancies in 2006 was 2.5 times that in 2005. And this number had 
been increasing since. In 2009, the number dropped a little due to the financial crisis. However, the number was still high. According to the statistics from the Ministry of Education, in 2009, there were 21,454 students studying in accounting-related departments in universities and 1,757 in vocational schools. Only $3.9 \%$ of these university students and $39.6 \%$ of vocational school students had found jobs in their own trade. Together they were still not enough to fill all the vacancies of accounting-related jobs in enterprises. Therefore, many non-professionals were doing these accounting-related jobs (Barrar et al., 2002).

Yuehua and Wie (2008) stated that most of the companies didn't have any limitations in departments of graduation and most of the rest companies preferred accounting-related department. The reason might be the advancement of accounting software, which lowers the standards of requirement for accounting personnel (Dockerill, 1981; Heathfield, 1997; Sian, 2009). Bahari and Ling (2009) had done an empirical research of the implementation process of accounting systems in small and medium enterprises. The result shows that small and medium enterprises' motive of implementing accounting systems was the demand from enterprises' own development. While enterprises expanded with increasing volume of business, purchase, sales and inventory management offered the most direct and efficient help to enterprises' management and business dealings. And computerization of the operation-level tasks led to the fastest effects with the lowest costs. This perfectly fit the management characteristics of small and medium enterprises' investments.

After analyzing from the aspect of job hunters, it is found that the average enrollment rate of the five years from $2005-2009$ was $61.3 \%$.

Noravesh et al. (2007) showed that the enrollment rate of accounting-related jobs has been stable since 2006. However, during the financial crisis, it unusually rose rapidly. The reason was the huge drop of number of job hunters while number of vacancies remained about the same. It was probably because job hunters thought there weren't many vacancies or average salary dropped. According to the statistics provided by the DirectorateGeneral of Budget, Accounting and Statistics, Executive Yuan, in January, 2009 salary in industry and service trade had reached the highest point since 2001. In some trades, salaries were doubled. However, due to the financial crisis, salaries started to drop after February. Till December, they had already dropped back to the standards in 2001 (Barrar et al., 2002).

The distribution of educational background of accounting-related job hunters.
Yuehua and Wie (2008) stated that through a survey of employment status from 2005-2007 with students graduated from the Department of Accounting Information; it is found that the percentage of serving as tax collectors or serving in accounting firms had been increasing year by year. The number of these cases was almost doubled. On the other hand, the percentage of serving as accountants or cashiers had greatly dropped from $50 \%$ in $2005-18 \%$ in 2007 , which was almost $1 / 3$. The percentage of serving as general professionals had sharply increased from $2.38 \%$ in $2005-20 \%$ in 2008, which was almost 10 times. It can be seen that the ratio of students graduated from accounting-related departments serving in their own professional field was still rather low.

Theory and applications of grey prediction: The grey theory was developed in 1979 by professor Ju-Long Deng from Huazhong University of Science and Technology, China. In March, 1982, an article titled "Control Problems of Grey System" was published in "System and Control Letters", an international magazine issued by North-Holland. That was the birth of the grey theory in the world. After over ten years of development and application by professor Dung and foreign/domestic scholars, this theory has been used in tens of fiends with plenty of research reports with achievements. Currently, known fields of application include environmental engineering, agriculture, communications, weather, construction, transportation, economics, medical treatments, education, geology, management and physical education. In Taiwan, there have been many research results by scholars in different fields such as information, electric engineering, machinery, automation, aeronautics and astronautics, civil engineering, water conservancy, building, industrial engineering, industrial education, commerce, transportation and communication, business management and physical education (Da et al., 2009; Li et al., 2007; Noravesh et al., 2007; Yamaguchi et al., 2007).

Mao and Chirwa (2004) from Bolton University, UK applied GM $(1,1)$ to predict the risk of death in car accidents in the US and the UK. The prediction was very close to the actual value (Li et al., 2007; Noravesh et al., 2007) applied grey prediction model to the samples of demands and sales in the global IC industry and found that grey prediction was perfect for short-term predictions. In 2007, scholars Akay and Atak (2007) applied grey prediction, due to the increasing electricity consumption in Turkey, to the total electricity consumption and industrial electricity consumption. The prediction obtained was much more 
accurate than predictions made with other methods. Youxin et al. (2009) Anhui applied revised grey model to predict the demand for electricity in Taiwan and significantly improved the accuracy of the original grey model.

\section{MATERIALS AND METHODS}

Predicting the trend of accounting-related job vacancies in Taiwan: Data for prediction were the accounting-related job vacancy data obtained from 1111 Job Bank. Grey mode GM $(1,1)$ was applied the accounting-related job vacancy data from 2005-2008 as the sample for test. The result was compared with the actually number of vacancies in 2009 to find out the accuracy rate. Then the model built was used to predict the numbers of accounting-related job vacancies and the trend in 2010 and 2011.

Predicting the development trend of accountingrelated jobs in Taiwan with grey prediction method: Because the dataset was huge, the unit adopted for prediction was "1000 persons".

\section{RESULTS}

The accuracy rate of the prediction model was 93.7485\% (Table 1). Compared with the actual number of job vacancies in 2009, which was 9,759, the accuracy rate was $77.07 \%$. Then the model built was applied to make predictions of the numbers of accounting-related job vacancies in 2010 and 2011.

The accuracy rate of the prediction model was $90.2476 \%$ (Table 2). The prediction of the number of job vacancies in 2010 was 11,375 . The development coefficient "a" was negative, which means the number of accounting-related job vacancies would continue to increase.

The model accuracy rate was $92.19 \%$ (Table 3). The prediction of the number of accounting-related job vacancies in 2011 was 12,333. The development coefficient "a" was negative, which means the number of accounting-related job vacancies would continue to increase.

According to the previous test and prediction results, in Taiwan, the number of accounting-related job vacancies would still stably increase in the future. Since the bookkeeper exams became national exams, the number of tax collectors has been increasing sharply. In the school where the author of this article serves, among the jobs the graduates of the Department of Accounting Information had got, accountants in accounting firms and tax collectors are the ones with the largest increase of number of cases. These two facts were consistent.
Table 1: The building process of the prediction

Model accuracy: $\mathrm{a}=-0.1667984758 ; \mathrm{b}=6.5743922637$

\begin{tabular}{llll} 
& $\mathrm{x}^{\wedge} 0(\mathrm{k})$ & $\mathrm{x} 0(\mathrm{k})$ & $\mathrm{e}(\mathrm{k}) \%$ \\
\hline $\mathrm{k}=1$ & & 2.87800 & \\
$\mathrm{k}=2$ & 7.6769 & 7.18800 & -6.8015 \\
$\mathrm{k}=3$ & 9.0704 & 9.94100 & 8.7579 \\
$\mathrm{k}=4$ & 10.7168 & 10.38500 & -3.1949 \\
$\mathrm{k}=5$ & 12.6621 & Average residual: $6.2515 \%$ \\
\hline
\end{tabular}

Table 2: Prediction of the number of accounting-related job vacancies in 2010

Model accuracy: $\mathrm{a}=-0.0813945106 ; \mathrm{b}=7.6500796800$

\begin{tabular}{llll} 
& $\mathrm{x}^{\wedge} 0(\mathrm{k})$ & $\mathrm{x} 0(\mathrm{k})$ & $\mathrm{e}(\mathrm{k}) \%$ \\
\hline $\mathrm{k}=1$ & & 2.87800 & \\
$\mathrm{k}=2$ & 8.2141 & 7.18800 & -14.2750 \\
$\mathrm{k}=3$ & 8.9106 & 9.94100 & 10.3648 \\
$\mathrm{k}=4$ & 9.6662 & 10.3850 & 6.9211 \\
$\mathrm{k}=5$ & 10.4859 & 9.75900 & -7.4488 \\
$\mathrm{k}=6$ & 11.3751 & \multicolumn{2}{c}{ Average residual $=9.7524 \%$} \\
\hline
\end{tabular}

Table 3: Prediction of the number of accounting-related job vacancies in 2011

Model accuracy: $\mathrm{a}=-0.0812687801 ; \mathrm{b}=7.6520774133$

\begin{tabular}{llll} 
& $\mathrm{x}^{\wedge} 0(\mathrm{k})$ & $\mathrm{x} 0(\mathrm{k})$ & $\mathrm{e}(\mathrm{k}) \%$ \\
\hline $\mathrm{k}=1$ & & 2.8780 & \\
$\mathrm{k}=2$ & 8.2153 & 7.1880 & -14.2915 \\
$\mathrm{k}=3$ & 8.9108 & 9.9410 & 10.3632 \\
$\mathrm{k}=4$ & 9.6652 & 10.3850 & 6.9311 \\
$\mathrm{k}=5$ & 10.4835 & 9.7590 & -7.4237 \\
$\mathrm{k}=6$ & 11.3710 & 11.3750 & 0.0348 \\
$\mathrm{k}=7$ & 12.3337 & \multicolumn{2}{c}{ Average residual $=7.8089 \%$} \\
\hline
\end{tabular}

\section{DISCUSSION}

The development of departments in (vocational) senior high schools and universities/colleges in Taiwan: In the recent years, with the decline of birth rate, running senior high schools and vocational senior high schools has become more difficult (Akay and Atak, 2007). Even universities/colleges have been influenced by the shortage of students. Most of universities/colleges are enrollment-oriented. They may revise the planning for departments in order to enroll more students. Traditional departments such as industrial departments and commercial departments are gradually losing their attraction and therefore can not recruit enough students. Thus many schools have given up industrial or commercial departments and added more service-trade-related departments such as department of tourism and department of catering in order to get more students. According to the statistics from the Ministry of Education, ROC, the number of students in departments related to tourism or catering, which was over 70,000, was three times that of students in traditional departments related to commerce. According to this, the electronic technology industry, 
the honor of Taiwan, will graduate face the issue of manpower shortest. It is the same for the 6 emerging industries which the government has been encouraging. And the development and achievements of the country's development will be seriously influenced.

Senior high schools and vocational senior high schools in Taiwan changed their traditional departments and it was because of the enrollment issue. It can be found from the statistics provided by the Ministry of Education that only very few (vocational) senior high schools which recruited only students in accountingrelated departments. And there were only 4,524 students studying in accounting-related departments. And there were 41,540 students studying in other departments related to commerce (Mao and Chirwa, 2004). However, there were up to 94,114 students studying in departments related to tourism or catering, the number was doubled. As previously mentioned, the major sources of manpower in enterprise accounting are senior high school and vocational school graduates. Nowadays, to adopt the changes of environment, (vocational) senior high schools have to consider enroll more students for service-trade-related departments. As a result, in Taiwan, there will be not enough professional manpower in the future and there will be too many manpower supplies in the tourism industry. After graduation, students can hardly find jobs. Although the service trade has been growing rapidly, the market is still too small for all the students graduated from schools in Taiwan.

\section{CONCLUSION}

School education shall meet enterprises' demands for manpower: Education and professional trainings are the keys to success. The manpower demands of the high-end agriculture, tourism, culture and creation, biotechnology and green energy industries among the 6 emerging industries can not be met with the current education structure in Taiwan. And the shortage of professionals in the medicine and health care industry is very serious. Not a lot of universities/colleges are developing their departments toward the 6 emerging industries. It's not enough if only enterprises are putting in efforts. After all, enterprises' competitiveness is a result of sufficiency of professional talents. The government should put more emphasis on the consistency of planning for schools and enterprises' demands.

Suggestions: There is no doubt that the best professionals in Taiwan come from national universities. Construction plans or industry upgrading plans promoted by the government are usually 5-year or 10-year plans. Before these plans are implemented, if cooperation with the Ministry of Education can be made to offer corresponding programs for 5-year or 10year government plans, when students graduate, plans are implemented. These tow aspects are linked together. Students' problem of job hunting would be reduced. And the right persons required by public constructions and industry upgrading can be found. Formosa Plastics and Hon Hai Technology Group are representative enterprises in Taiwan. They both founded schools to cultivate talents they need. They don't have to depend on graduates from other schools. This way, enterprises not only know what kinds of talents they need, but also cultivate the talents they want. In addition, students may get the chance of long-term cooperation with the enterprises. Their loyalty would be higher than regular students and they can identify themselves with the enterprises. Turnover would be lower, manpower cost would be reduced and most important of all, enterprises' manpower demands can be met.

In Taiwan, education is well-developed with good ability to cultivate talents. If the direction can be adjusted toward the development of the nation, Taiwan's competitiveness in the world would definitely be improved. Nowadays, in order to survive, schools plan for departments which meet students' demands so they would be more willing to attend. Enterprises' demands for talents are ignored. This is a waste of national education resources and it can not help with the competitiveness of the nation and enterprises. Therefore, the issue of whether the country should guide the direction of education is something worth thinking about.

\section{REFERENCES}

Akay, D. and M. Atak, 2007. Grey prediction with rolling mechanism for electricity demand, forecasting of Turkey. Energy, 32: 1670-1675. DOI: 10.1016/j.energy.2006.11.014

Bahari, A.B.M. and L.M. Ling, 2009. Introducing tax education in non-accounting curriculum in higher education: Survey evidence. J. Fin. Rep. Account., 7: 37-51. DOI: 10.1016/j.energy.2006.11.014

Barrar, P., D. Wood, J. Jones and M. Vedovato, 2002b. The efficiency of accounting service provision. Bus. Process Manage. J., 8: 195-217. DOI: $10.1108 / 14637150210428925$

Da, L., N. Dongxiao, L. Yuanyuan and C. Guanjuan, 2009. Combined models for day-ahead electricity price forecasting based on improved gray correlation methodology. Kybernetes, 38: 354-361. DOI: $10.1108 / 03684920910944047$ 
Dockerill, P., 1981. Small systems for small businesses. Ind. Manage. Data Syst., 81: 33-35. DOI: 10.1108/eb057205

Heathfield, P., 1997. SME business leaders need powerful on-board computers. Indus. Manage. Data Syst., 97: 233-235. DOI: 10.1108/02635579710176803

Li, G.D., D. Yamaguchi and M. Nagai, 2007. Application of grey-based rough decision-making approach to suppliers selection. J. Model. Manage., 2: 131-142. DOI: 10.1108/17465660710763416

Mao, M. and E.C. Chirwa, 2004, Application of grey model GM $(1,1)$ to vehicle fatality risk estimation. Tech. Forecast. Soc. Change, 73: 588-604. DOI:10.1016/j.techfore.2004.08.004

Noravesh, I., Z.D. Dilami and M.S. Bazaz, 2007. The impact of culture on accounting: Does gray's model apply to Iran? Rev. Account. Finance, 6: 254-272. DOI: 10.1108/14757700710778009
Sian, S.C.R., 2009. UK small owner-managed businesses: Accounting and financial reporting needs. J. Small Bus. Enterp. Dev., 16: 289-305. DOI: $10.1108 / 14626000910956065$

Yamaguchi, D., G.D. Li and M. Nagai, 2007. A greybased rough approximation model for interval data processing. Inform. Sci. Int. J., 177: 4727-4744. DOI: 10.1016/j.ins.2007.05.022

Youxin, L., W. Xiao, L. Min and C. Anhui, 2009. Grey dynamic model GM $(1, N)$ for the relationship of cost and variability. Kybernetes, 38: 435-440. DOI: 10.1108/03684920910944137

Yuehua, C. and Y. Wie, 2008. Study on investment scale control of urban construction process by the method of grey systems. Kybernetes, 37: 1272-1278. DOI: 10.1108/03684920810907553.3 